\title{
Drug dispensing systems in Gaza hospitals: a comparative study
}

\author{
M. Al Adham and B. Abu Hamad ${ }^{2}$
}

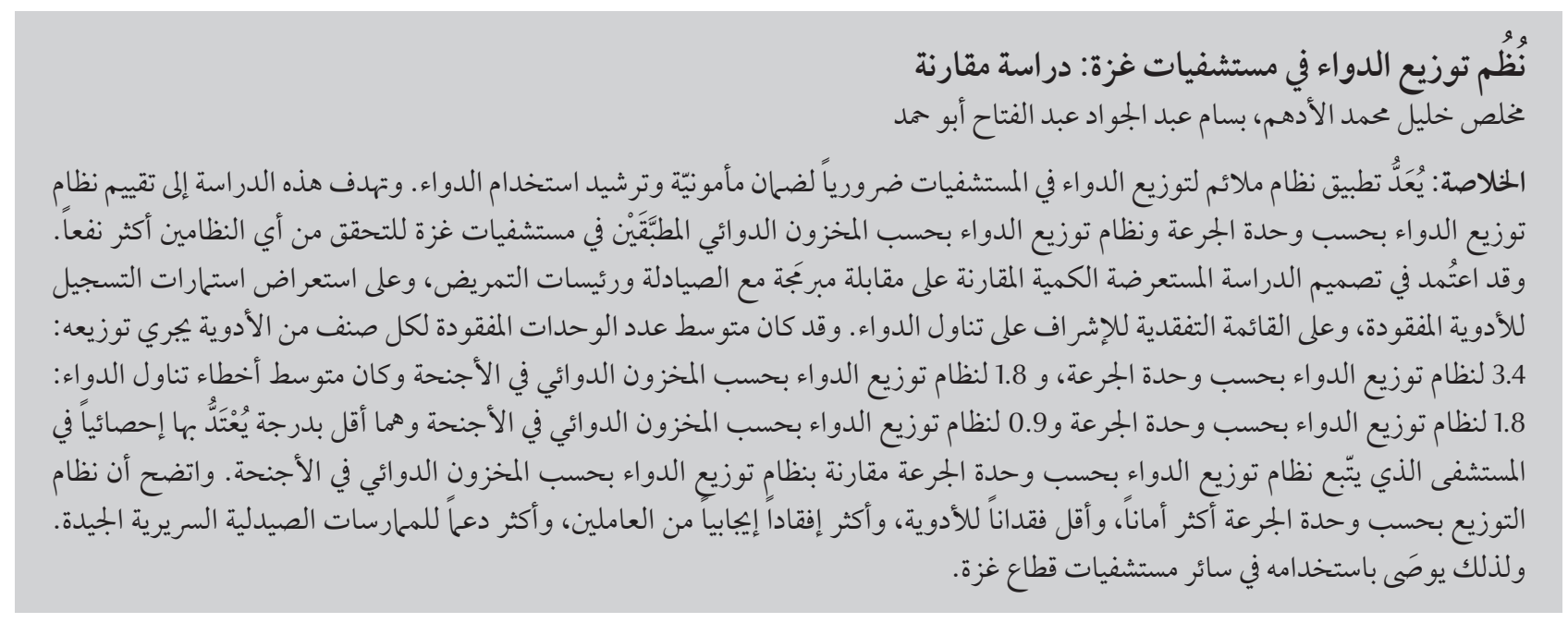

ABSTRACT Implementing an appropriate drug dispensing system in hospitals is essential to ensure the safe and rational use of drugs. This study aimed to assess the unit-dose drug dispensing system (DDS) and the ward-stock DDS utilized in Gaza hospitals to ascertain which system is more beneficial. The quantitative, comparative cross-sectional design utilized structured interviews with pharmacists and head nurses, missing drug registration sheets and drug administration observation checklists. The number of missing units per drug item dispensed (mean 3.4 and 1.8 respectively) and medication administration errors per patient (mean 1.8 and 0.9 respectively) were statistically significantly lower in the hospital using the unit-dose DDS than the ward-stock DDS. The unitdose DDS appeared to be safer, with fewer missing drugs, was more positively perceived by staff and was more supportive of good clinical pharmacy practice. Its use in other hospitals in the Gaza Strip is recommended.

\section{Systèmes de dispensation de médicaments dans deux hôpitaux de Gaza : étude comparative}

RÉSUMÉ La mise en œuvre d'un système de dispensation de médicaments adapté aux hôpitaux est essentielle pour garantir leur utilisation rationnelle et sans risque. La présente étude visait à comparer le système de dispensation à délivrance journalière individuelle et nominative des médicaments au système de dispensation à délivrance globale par unité de soins dans deux hôpitaux de Gaza pour savoir lequel était le plus avantageux. Le plan de l'étude quantitative, comparative et transversale a intégré les résultats des entretiens structurés réalisés auprès des pharmaciens et des cadres infirmiers, les données sur les fiches d'enregistrement des médicaments manquantes et les listes de contrôle des observations concernant l'administration des médicaments. Le nombre d'unités manquantes par type de médicament dispensé (moyenne 3,4 et 1,8 respectivement) et le nombre d'erreurs d'administration médicamenteuse par patient (moyenne 1,8 et 0,9 respectivement) étaient significativement inférieurs au niveau statistique dans l'hôpital utilisant le système de dispensation à délivrance journalière individuelle et nominative des médicaments que dans l'autre. Le système de dispensation à délivrance journalière individuelle et nominative des médicaments s'est révélé être plus sûr, moins générateur de médicaments manquants, mieux perçu par le personnel et davantage adapté aux bonnes pratiques de pharmacie hospitalière. Son utilisation dans d'autres hôpitaux de la Bande de Gaza est recommandée. 


\section{Introduction}

The pharmacy sector is important in any country because it consumes a high proportion of health system expenditure [1]. Therefore, it is a challenge for governments to ensure easy access to a safe and stable supply of pharmaceuticals at the lowest possible cost [2]. A high expenditure on drugs is notable in the Palestinian health system where it reached $22.6 \%$ of the Ministry of Health $(\mathrm{MOH})$ running costs in 2005 [3]. Hospital pharmacies are the largest consumers in the pharmacy sector, so it is important for policy-makers to be aware of the importance of providing effective pharmacy services with rational and safe use of medications [1]. Clinical pharmacy services are the building blocks of modern hospital pharmacy, and hospital pharmacists are a vital part of the clinical team, helping to ensure that drugs are used in the best way from the safety, efficacy and economic points of view [4].

Adoption of a proper drug dispensing system (DDS) is a top priority for any hospital to ensure an effective drug management cycle in that hospital $[5,6]$. There are many types of DSS. In a wardstock DDS, drugs are dispensed from the pharmacy to the hospital departments and stored in the departments' stocks and then used by nurses according to physicians' orders. In a unit-dose DDS, drugs are dispensed in amounts that fulfil the needs of each individual patient for only 24 hours [5]. The unitdose DDS was developed in the 1960s to support nurses in administration of medication, to provide nurses and pharmacists with more time for patient care and to reduce wastage of increasingly expensive medications. Now unit-dose dispensing of medications is standard practice in many hospitals around the world [6].

The aim of this study in Gaza, Palestine, was to assess which DDS was more appropriate based on a comparison between a hospital using the unit-dose
DDS and another using a ward-stock DDS. The study explored the percentage of missing drugs in both systems and which system was safer by calculating the rates of medication administration errors and it also assessed the level of clinical pharmacy interventions and staff perceptions about the 2 systems.

\section{Methods}

\section{Study design and setting}

This was a quantitative, comparative cross-sectional study comparing 2 hospitals that used different DDSs for their pharmaceutical services for patients. AlShifa hospital was the largest hospital in the Palestinian Territory and like most hospitals in Gaza used the ward-stock DDS. The European Gaza hospital was a large hospital in Gaza which used the unit-dose DDS. The study was carried out in the 2 main departments of both hospitals (medical and surgical).

\section{Study population}

The study sample included all the medical records $(n=327)$ of patients who were hospitalized in the 4 selected departments of the 2 hospitals in July 2008. In addition, 1096 observations were made of drug administration by nurses in the selected departments. To explore users' perceptions about the different systems all pharmacists and head nurses working in the target hospitals $(n=92)$ were asked to participate in structured interviews. The total number of pharmacists at both hospitals was 36 (22 in Al-Shifa hospital and 14 in European Gaza hospital). At each site, there was a pharmacy director and deputy pharmacy director who performed managerial tasks while the other pharmacist performed the other hospital pharmacy activities.

\section{Data collection}

The researcher and a trained assistant (pharmacist) collected the data. The structured interview consisted of 61 close-ended questions that were mainly concerned with assessing participants' perceptions and practices in reference to drug dispensing and management, and was administered by the principal researcher. Names and quantities of drugs prescribed and dispensed to hospitalized patients during the study period (July 2008) were obtained from the medical records and documented in a drug registration sheet and then compared with the amounts of drugs dispensed from the pharmacy to the same departments (obtained from pharmacy records) over the same period. Any drug that was dispensed from the pharmacy and neither registered in the medical records nor added to the stock was considered as a missing drug. An observation checklist for medication administration errors was used to check the number of drug administration errors out of the total number of administration processes that took place in the study period. Nurses administering medications were classified according to the " 5 wrongs" of medication errors (i.e. the opposite of the "5 rights" [7]): wrong drug (administration of medication other than the one prescribed); wrong dose (amount of medication given was greater or less than the prescribed dose; extra dose and formulation errors were included); wrong time (administration of medication to the patient 30 minutes before or after the prescribed time); wrong route (administration of medication via a different route than the prescribed one); and wrong patient (administration of medication for a patient other than for whom it was prescribed).

Thestudyfollowedstandardresearch ethical principles, and approval from the National Committee on Research Ethics was obtained. Administrative approval from the general directorate of hospitals was obtained before starting data collection. Participation was voluntary and consent was obtained from all pharmacists and head nurses before administration of the structured interviews. 


\section{Data analysis}

The data were analysed using SPSS, version 13. Frequency tables were done to illustrate the main characteristics of the study respondents. Cross-tabulations and chi-squared tests were carried out to examine the differences between the 2 hospitals. Student $t$-tests were done to compare the means of the missing drugs and the medications administration errors between the 2 hospitals. A Pvalue $<0.05$ was considered statistically significant.

\section{Results}

\section{Subjects' characteristics}

Out of the 92 pharmacists and head nurses, 87 (94.6\%) responded. Of the respondents $40 \%$ were pharmacists while $60 \%$ were head nurses. Males represented $63 \%$ of subjects. The age distribution was $16.1 \% \leq 30$ years, $50.6 \%$ $31-40$ years and $33.3 \% 41+$ years. Twothirds of the respondents (67.7\%) were working in Al-Shifa hospital and 33.3\% in European Gaza hospital.

\section{Respondents' perceptions and practices}

In general, the unit-dose DDS implemented at European Gaza hospital was more positively perceived by the respondents than the ward-stock DDS implemented at Al-Shifa hospital (Table 1). Most respondents at both hospitals had experienced drug shortages, mainly due to shortages at the Gaza central drug stores. However, this shortage of drugs was mainly a problem for newly admitted patients at the European Gaza hospital, while it was faced for both newly and previously admitted cases at Al-Shifa hospital, a difference that was statistically significant $\left(\chi^{2}=\right.$ $15.9, P=0.001$ ).

The need for extra staff to deal with pharmaceuticals was more evident at Al-Shifa hospital, where nearly 58.6\% of the respondents reported that they needed more employees to meet the system requirements compared with only 37.9\% at the European Gaza hospital.

Significantly more positive perceptions were held among respondents implementing the unit-dose DDS than their counterparts implementing the ward-stock DDS regarding the time needed to manage medications; $100.0 \%$ of nurse at the European Gaza hospital reported normal time scales (i.e. their perception of the time needed to manage the medications at their departments) while $69.0 \%$ at Al-Shifa hospital reported long time scales $\left(\chi^{2}=\right.$ $19.8, P=0.001)$. The great majority of the respondents at the European Gaza hospital (86.2\%) were returning unused drugs to the pharmacy, while only $36.2 \%$ of respondents at Al-Shifa hospital did that $\left(\chi^{2}=10.8, P=0.002\right)$. Almost all respondents at the European Gaza hospital and only half of respondents at Al-Shifa hospital reported checking the ward-stocks of drugs for expiry, which was a positive point at the European Gaza hospital $\left(\chi^{2}=8.1, P=0.044\right)$. Furthermore, satisfaction about the DDS in their department and the desire to continue its use was statistically significantly higher at the European Gaza hospital than Al-Shifa hospital (93.1\% and $60.3 \%$ of respondents respectively) $\left(\chi^{2}=10.1, P=0.001\right)$.

\section{Clinical pharmacy-related activities}

As illustrated in Table 2, more than 90\% of the pharmacists at both hospitals were visiting the hospital wards $1-3$ times per month, with no clear differences between the hospitals in this regard. Surprisingly, $72.8 \%$ of Al-Shifa hospital pharmacists reported never checking the patients' charts to assess the congruency between drugs prescribed and disease conditions. In contrary, at the European Gaza hospital, around half of the pharmacists reported often checking patients' charts for conformity of the drugs with the diagnosis, and the difference between the hospitals in this regard was statistically significant $\left(\chi^{2}\right.$ $=15.8, P=0.003)$. In addition, most pharmacists at the European Gaza hospital (92.9\%) reported that they often checked the patients' charts for suitability of the drug dose, while at Al-Shifa hospital only $59.1 \%$ of them reported performing that $\left(\chi^{2}=21.3, P=\right.$ 0.001). Although checking drug-drug interactions was not performed well at either of the hospitals, it was carried out significantly more often at the European Gaza hospital than at Al-Shifa hospital $\left(\chi^{2}=14.2, P=0.007\right)$. Table 2 shows that the percentage of pharmacists who did not check the ward stocks before dispensing the medication order was higher in Al-Shifa hospital (72.7\%) than the European Gaza hospital (42.9\%). The majority of pharmacists at Al-Shifa hospital (91.0\%) reported that they had never prepared any written guidelines about drug use, while only $7.1 \%$ of the European Gaza hospital pharmacists had not done this $\left(\chi^{2}=26.2, P=0.001\right)$. Regarding supervising the pharmacy work of less experienced staff, a good percentage of pharmacists at both hospitals reported performing this as part of the routine work of the hospital. The level of pharmacists' participation in training activities about drugs at both hospitals was very low ( $90.9 \%$ and $71.4 \%$ respectively had never done this).

\section{Record reviews}

The percentage of missing drugs at Al-Shifa hospital which was utilizing the ward-stock DDS was which higher $(5.0 \%)$ than at the European Gaza hospital utilizing the unit-dose DDS (2.9\%). Table 3 shows that the mean number of missing units of drug type per month (i.e. dispensed from the pharmacy to the nursing departments during the study period but not found either in the patients files or in the departments stock) was higher overall at Al-Shifa hospital (3.4) than at the European Gaza hospital (1.8). The difference between the 2 hospitals was statistically significant $(t=2.5, P=$ 


\begin{tabular}{|c|c|c|c|c|c|c|}
\hline \multirow[t]{3}{*}{ Variable } & \multicolumn{4}{|c|}{ Hospital (DDS system) } & \multirow[t]{3}{*}{$\chi^{2}$-value } & \multirow[t]{3}{*}{$P$-value } \\
\hline & \multicolumn{2}{|c|}{$\begin{array}{c}\text { Al-Shifa } \\
\text { (ward-stock) } \\
(n=58)\end{array}$} & \multicolumn{2}{|c|}{$\begin{array}{l}\text { European Gaza } \\
\text { (unit-dose) } \\
(\boldsymbol{n}=29)\end{array}$} & & \\
\hline & No. & $\%$ & No. & $\%$ & & \\
\hline Drug shortages experienced in the last year & & & & & 8.2 & 0.084 \\
\hline Seldom & 3 & 5.2 & 7 & 24.2 & & \\
\hline Sometimes & 44 & 75.9 & 21 & 72.4 & & \\
\hline Often & 11 & 18.9 & 1 & 3.4 & & \\
\hline Patients most affected by drug shortages & & & & & 15.9 & 0.001 \\
\hline Newly admitted cases & 18 & 31.0 & 22 & 75.9 & & \\
\hline Previously admitted cases & 3 & 5.2 & 0 & 0.0 & & \\
\hline Both & 37 & 63.8 & 7 & 24.1 & & \\
\hline DDS requires extra staff & & & & & 3.6 & 0.301 \\
\hline Disagree & 16 & 27.6 & 12 & 41.4 & & \\
\hline Neither agree nor disagree & 8 & 13.8 & 6 & 20.7 & & \\
\hline Agree & 34 & 58.6 & 11 & 37.9 & & \\
\hline Time needed for nurses to manage medications & & & & & 19.8 & 0.001 \\
\hline Long & 40 & 69.0 & 0 & 0.0 & & \\
\hline Normal & 18 & 31.0 & 29 & 100.0 & & \\
\hline Method of dealing with unused drugs on the wards & & & & & 10.8 & 0.002 \\
\hline Returned to pharmacy & 21 & 36.2 & 25 & 86.2 & & \\
\hline Remain in ward & 37 & 63.8 & 4 & 13.8 & & \\
\hline $\begin{array}{l}\text { Perception of presence of high number of missing } \\
\text { drugs (irrational use) }\end{array}$ & & & & & 15.3 & 0.002 \\
\hline Disagree & 26 & 44.8 & 24 & 82.8 & & \\
\hline Neither agree nor disagree & 13 & 22.4 & 4 & 13.8 & & \\
\hline Agree & 19 & 32.8 & 1 & 3.4 & & \\
\hline Perception of rate of medication errors in hospital & & & & & 1.7 & 0.63 \\
\hline Low & 32 & 55.0 & 9 & 31.0 & & \\
\hline Very low & 26 & 45.0 & 20 & 69.0 & & \\
\hline Report medication errors that may happen & & & & & 2.31 & 0.315 \\
\hline Never & 49 & 83.0 & 21 & 72.5 & & \\
\hline Seldom & 9 & 17.0 & 8 & 27.5 & & \\
\hline \multicolumn{7}{|l|}{ Check the ward-stock drugs for expiry } \\
\hline Yes & 32 & 55.0 & 29 & 100.0 & 8.1 & 0.044 \\
\hline No & 26 & 45.0 & 0 & 0.0 & & \\
\hline \multicolumn{7}{|l|}{ Satisfied with the DDS and wish to continue using it } \\
\hline Yes & 35 & 60.3 & 27 & 93.1 & 10.13 & 0.001 \\
\hline No & 23 & 39.7 & 2 & 6.9 & & \\
\hline
\end{tabular}

$n=$ number of pharmacists and head nurses.

0.015). The mean number of missing drugs in the medical department of AlShifa hospital was significantly higher than in the European Gaza hospital (3.8 and 1.4 respectively) $(t=2.1, P=0.038)$, but in the surgical departments the means of missing drugs were 2.8 and 2.3 respectively, which was not significantly different. The main types of missing drugs were diclofenac sodium $(75 \mathrm{mg}$ ampoules) and amoxycillin (500 mg capsules) at Al-Shifa hospital, while they were antiacid tablets and cephalexine (500 mg capsules) at the European Gaza hospital. At both sites, the drugs most often missing corresponded to the drugs most often dispensed during the study period. 


\begin{tabular}{|c|c|c|c|c|c|c|}
\hline \multirow[t]{3}{*}{ Variable } & \multicolumn{4}{|c|}{ Hospital (DDS system) } & \multirow[t]{3}{*}{$\chi^{2}$-value } & \multirow[t]{3}{*}{$P$-value } \\
\hline & \multicolumn{2}{|c|}{$\begin{array}{c}\text { Al-Shifa } \\
\text { (ward-stock) } \\
(n=22)\end{array}$} & \multicolumn{2}{|c|}{$\begin{array}{c}\text { European Gaza } \\
\text { (unit-dose) } \\
(n=14)\end{array}$} & & \\
\hline & No. & $\%$ & No. & $\%$ & & \\
\hline Frequency of visits to wards per month & & & & & 2.85 & 0.416 \\
\hline $1-3$ & 21 & 95.5 & 13 & 92.9 & & \\
\hline $4-6$ & 1 & 4.5 & 1 & 7.1 & & \\
\hline $\begin{array}{l}\text { Check prescriptions for conformity of drug therapy } \\
\text { with diagnosis }\end{array}$ & & & & & 15.8 & 0.003 \\
\hline Never & 16 & 72.8 & 1 & 7.1 & & \\
\hline Sometimes & 3 & 13.6 & 7 & 50.0 & & \\
\hline Often & 3 & 13.6 & 6 & 42.9 & & \\
\hline Check prescriptions for suitable drug dose & & & & & 21.3 & 0.001 \\
\hline Never & 4 & 18.2 & 1 & 7.1 & & \\
\hline Sometimes & 5 & 22.7 & 0 & 0.0 & & \\
\hline Often & 13 & 59.1 & 13 & 92.9 & & \\
\hline Check prescriptions for drug-drug interactions & & & & & 14.2 & 0.007 \\
\hline Never & 17 & 77.4 & 2 & 14.3 & & \\
\hline Seldom & 3 & 13.6 & 11 & 78.6 & & \\
\hline Often & 2 & 9.0 & 1 & 7.1 & & \\
\hline Check ward-stock before dispensing the order & & & & & 4.28 & 0.118 \\
\hline Never & 16 & 72.7 & 6 & 42.9 & & \\
\hline Seldom & 6 & 27.3 & 8 & 57.1 & & \\
\hline Prepare guidelines about drugs & & & & & 26.15 & 0.001 \\
\hline Never & 20 & 91.0 & 1 & 7.1 & & \\
\hline Sometimes & 1 & 4.5 & 10 & 71.4 & & \\
\hline Often & 1 & 4.5 & 3 & 21.5 & & \\
\hline $\begin{array}{l}\text { Check and supervise the pharmacy work of less } \\
\text { experienced pharmacists }\end{array}$ & & & & & 4.98 & 0.288 \\
\hline Never & 1 & 4.5 & 2 & 14.3 & & \\
\hline Sometimes & 4 & 18.1 & 5 & 35.7 & & \\
\hline Often & 9 & 40.9 & 6 & 42.9 & & \\
\hline Always & 8 & 36.5 & 1 & 7.1 & & \\
\hline $\begin{array}{l}\text { Participate in teaching programmes in the hospital } \\
\text { about drugs }\end{array}$ & & & & & 2.69 & 0.261 \\
\hline Never & 20 & 90.9 & 10 & 71.4 & & \\
\hline Seldom & 2 & 9.1 & 4 & 28.6 & & \\
\hline
\end{tabular}

Always $=91 \%-100 \%$ of occasions; often $=42 \%-71 \%$ of occasions; sometimes $=11 \%-33 \%$ of occasions; seldom $=7 \%-8 \%$ of occasions; never $0 \%-2 \%$ of occasions . $n=$ number of pharmacists.

\section{Field observations}

The percentage of medication administration errors at Al-Shifa hospital (9.7\%) was higher than it at the European Gaza hospital (6.0\%). As illustrated in Table 4 , the mean number of medication administration errors (per patient) was significantly higher at Al-Shifa hospital using the ward-stock DDS (1.8) than at the European Gaza hospital using the unit-dose DDS (0.9) $(t=2.1, P$ $=0.038)$. "Wrong time" errors were the most frequently observed (mean 1.5 and 0.7 respectively) followed by "wrong dose" errors and "wrong drug" errors. However, "wrong patient" and "wrong route" errors were negligible. Most error types were greater in the hospital using the ward-stock DDS than the hospital using the unit-dose DDS, except for the "wrong drug" errors, but the differences between the 2 hospitals regarding specific types of drug error did not reach statistical significance. 


\begin{tabular}{|c|c|c|c|c|}
\hline Hospital (DDS system) & $\begin{array}{l}\text { No. of dispensed drug } \\
\text { items }\end{array}$ & $\begin{array}{l}\text { Mean (SD) no. of missing } \\
\text { units per drug item }\end{array}$ & $t$-value & $P$-value \\
\hline Both wards & & & 2.45 & 0.015 \\
\hline Al-Shifa (ward-stock) & 162 & $3.4(3.7)$ & & \\
\hline European Gaza (unit-dose) & 202 & $1.8(4.3)$ & & \\
\hline Medical ward & & & 2.1 & 0.038 \\
\hline Al-Shifa (ward-stock) & 91 & $3.8(8.6)$ & & \\
\hline European Gaza (unit-dose) & 114 & $1.4(3.5)$ & & \\
\hline Surgical ward & & & 0.672 & 0.503 \\
\hline Al-Shifa (ward-stock) & 71 & $2.8(5.2)$ & & \\
\hline European Gaza (unit-dose) & 88 & $2.3(5.2)$ & & \\
\hline
\end{tabular}

$S D=$ standard deviation.

\section{Discussion}

In this study males were more involved in the workforce than their female counterparts, which corresponds with the level of men's involvement in the workforce in the Gaza Strip [8] and implies that greater enrolment of women needs be promoted. Most head nurses and pharmacists were below the age of 40 years and this reflects the trend towards expansion in the health services in Palestine which took place after the establishment of the Palestinian National Authority in 1994. The expansion in the health services was associated with the recruitment of a relatively young workforce. This young generation provides an opportunity for the health care system in term of investment in capacity-building. More respondents were from Al-Shifa hospital and this corresponds with the size of the 2 hospitals [9].

This study showed that positive perceptions and appropriate practices of nurses and pharmacists were more common in the hospital using the unitdose DDS than the ward-stock DDS. Hence, the unit-dose DDS meets the 2 important dimensions of quality (quality of facts and quality of perceptions) and this justifies its universal use. The literature indicates that the unit-dose DDS is safer, more economic and more positively perceived by staff [6].
Our study showed that the level of clinical pharmacy-related activities was slightly better at the European Gaza hospital than it at Al-Shifa hospital. Collectively, the level of clinical pharmacyrelated activities in both hospitals was low. Checking prescriptions for the suitability of the drug to the disease condition and checking the suitability of drug dose was done better in the hospital with the unit-dose DDS than the ward-stock DDS. It suggests that the unit-dose DDS gives pharmacists a better chance to carry out clinical pharmacy-related activities such as reviewing patients' charts for drug history, suitability of drugs, suitability of dose and possible drug interactions,

\begin{tabular}{|c|c|c|c|c|}
\hline Hospital (DDS system) & No. of observations & $\begin{array}{l}\text { Mean (SD) no. of } \\
\text { errors per patient }\end{array}$ & $t$-value & $P$-value \\
\hline All types & & & 2.127 & 0.038 \\
\hline Al-Shifa (ward-stock) & 600 & $1.8(1.3)$ & & \\
\hline European Gaza (unit-dose) & 496 & $0.9(0.6)$ & & \\
\hline Wrong drug & & & -0.64 & 0.524 \\
\hline Al-Shifa (ward-stock) & 1 & $0.03(0.2)$ & & \\
\hline European Gaza (unit-dose) & 2 & $0.07(0.3)$ & & \\
\hline Wrong dose & & & 1.43 & 0.158 \\
\hline Al-Shifa (ward-stock) & 9 & $0.3(0.5)$ & & \\
\hline European Gaza (unit-dose) & 4 & $0.1(0.4)$ & & \\
\hline Wrong time & & & 1.82 & 0.073 \\
\hline Al-Shifa (ward-stock) & 48 & $1.5(2.2)$ & & \\
\hline European Gaza (unit-dose) & 22 & $0.7(0.7)$ & & \\
\hline
\end{tabular}

$S D=$ standard deviation 
which are among their main clinical pharmacy activities [10]. Other clinical pharmacy-related activities were regarded as weak points in both systems and require strengthening by increasing the frequency of pharmacists' visits to the wards. In modern pharmacy practice, specialized pharmacists are advised to visit each hospital ward daily to maximize the benefits of the medications and also to promote the pharmacists' role in direct patient care [11].

The results of this study illustrated that the percentage of missing drugs in the hospital with the ward-stock DDS was higher than at the hospital using the unit-dose DDS. Our results are consistent with those of a study in Croatia which found that implementation of a unit-dose DDS contributed to rationalization of drug consumption and reductions in missing drugs [12]. They also agree with a study in the United States that found that drug losses were higher in ward-stock DDSs than in unit-dose DDSs [13]. The consistency between the results of different studies highlights the importance of adopting the unit-dose DDS in other Palestinian hospitals. Health planners and policymakers need to take active steps towards standardizing DDSs at the Palestinian hospitals to increase drug safety and rational drug use.

The results of this study showed that the rate of medication administration errors was greater in the hospital using ward-stock dispensing than in the hospital using unit-dose dispensing. It can be concluded that the unit-dose DDS is more beneficial to patient safety than the ward-stock DDS. This result agrees with many studies reported in the literature [14-16]. However, our results contradict those of a study that compared the rate of medication errors at an American hospital using the unit-dose DDS and a British hospital using the traditional ward-stock DDS, and found that the rate of medication errors was higher in the American hospital [17]. The study results also clarified that time errors were the most frequently observed type of medication administration errors in both DDSs. Although time errors in particular and medication administration errors in general are minor and may to have few consequences, some serious errors may be life-threatening. Therefore greater follow-up and attention should be paid to reducing medication errors, including the most commonly found time-related errors.

There were some limitations to the study including the unsettled general political situation in the Gaza Strip, the limited scientific resources and literature review about DDSs, and the long distance between the 2 study sites which contributed to the relatively high research budget.

\section{Conclusion and recommendations}

This study typifies the operational research approach, which aims to support evidence-based decision-making. In the Palestinian health system, both the unit-dose DDS and ward-stock DDS are still in use. Although many international studies showed that the unit-dose DDS is safer, more effective and more efficient than other systems in general and the ward-stock DDS in particular, the debate about the appropriate DDS is still ongoing in the Palestinian $\mathrm{MOH}$. This study has contributed to the evidence that the unit-dose DDS is associated with more rational drug use, better patient safety, more clinical pharmacy-related interventions and better perceptions and practices by nurses and pharmacists. This implies that the unit-dose DDS is appropriate and needs to be adopted as the standard dispensing practice in all Palestinian hospitals.

\section{References}

1. Pudjaningsih D, Santoso B. Self-monitoring instrument to improve the efficiency of drug management in hospital pharmacy. Indonesia, Gadiah Mada University, 2002.

2. Smith F. Community pharmacy in Ghana: Enhancing the contribution to primary health care. Health Policy and Planning, 2004, 19:234-241.

3. Health status in Palestine. Annual report. Ramallah, Palestine, Palestinian Health Information Center, Ministry of Health, 2005.

4. Wilson G, Tsui M. Hospital Pharmacy Services Provision in Australia. American Journal of Health-System Pharmacy, 2000, 57:677-680.

5. Anacleto T et al. Medication errors and drug-dispensing systems in a hospital pharmacy. Clinics (Sao Paulo, Brazil), 2005, 60:349-363.

6. Murray M, Shojania K. Unit-dose drug distribution systems. American Journal of Health-System Pharmacy, 2000, 56:101109.
7. Timby BK, ed. Fundamental skills and concepts in patient care, 7th ed. Philadelphia, Lippincott, Williams and Wilkins, 2003.

8. Population, housing, and establishment census 2007. Ramallah, Palestine, Palestinian Central Bureau of Statistics, 2007.

9. Health status in Palestine, Annual Report. Ramallah, Palestine, Palestinian Health Information Center, Ministry of Health, 2003.

10. Hamai T et al. Work measurement in clinical pharmacists' activities. Japanese Journal of Pharmaceutical Health Care and Sciences, 2001, 27:193-204.

11. Bryony $\mathrm{D}$ et al. When should pharmacists visit their wards? An application of simulation to planning hospital pharmacy services. Health Care Management Science, 2004, 2:35-42. >

12. Vrca B et al. Utjecaj primjene sustava raspodjele jedinicne terapije na potrosnju lijekova [The effect of implementation of a unit-dose drug distribution system on drug consumption]. Lijecnicki Vjesnik, 2000, 122:110-118. 
13. Barker N, Heller M. The development of centralized unit-dose dispensing system for UAMC. American Journal of Hospital Pharmacy, 1994, 21:609-625.

14. Fontan J et al. Medication errors in hospitals: computerized unit-dose drug dispensing system versus ward-stock dist. system. Pharmacy World and Science, 2003, 25:112-117.

15. Taxis K, Dean B, Barber N. Hospital drug dispensing systems in the UK and Germany: a study of medication errors. Pharmacy World and Science, 1999, 21:25-31.
16. Mc Nally M, Page A, Bruce V. Failure-mode and effects analysis in improving a drug distribution systems. American Journal of Health-System Pharmacy, 1997, 54:171-177.

17. Dean $\mathrm{S}$ et al. Comparison of medication errors in an American and a British hospitals. American Journal of Health-System Pharmacy, 1995, 52:2543-2549.

\section{Third International Conference for Improving Use of Medicines}

The Third International Conference for Improving Use of Medicines: Informed Strategies, Effective Policies, Lasting Solutions will be held from 14 to 18 November, 2011 in Antalya, Turkey.

The conference will focus on use of medicines in low- and middle-income countries, and will be highly interactive and designed to produce actionable results. It aims to present and summarize knowledge about ways to improve medicines use and health, especially for vulnerable populations. Participants will help to shape evidence-based policy recommendations and a future research agenda on these topics.

Half-day conference sessions will cover major focus areas in the health care system where changes to improve medicines use take place at the global, regional, national, institutional, health provider, consumer and community levels. These areas include:

- Access (public and private sector, production, intellectual property, generics)

- Policy, regulation, governance (guidelines, essential medicines lists, health reform, drug quality, promotion, transparency)

- Economics, financing, insurance systems (cost, affordability, incentives, medicines coverage)

- Maternal and child health (IMCI, paediatric medicines)

- Chronic care (diabetes, hypertension, mental health, adherence)

- $\mathrm{HIV} / \mathrm{AIDS}, \mathrm{TB}$

- Malaria

- Drug resistance (surveillance, containment, drug development)

Further information about the conference can be found at: http://www.inrud.org/ICIUM/Conference-Overview.cfm 